\title{
Article \\ Efficient Synthesis of Methyl Methacrylate by One Step Oxidative Esterification over Zn-Al-Mixed Oxides Supported Gold Nanocatalysts
}

\author{
Huayin $\mathrm{Li}^{1}$, Yuan Tan ${ }^{1, *}$, Xingkun Chen ${ }^{1}$, Wenshao Yang ${ }^{1}$, Chuanqi Huang ${ }^{1}, \mathrm{Jie} \mathrm{Li}^{1}$ and Yunjie Ding ${ }^{1,2,3, *}$ \\ 1 Hangzhou Institute of Advanced studies, Zhejiang Normal University, Hangzhou 311231, China; \\ lihuayin@zjnu.edu.cn (H.L.); cxklned@zjnu.cn (X.C.); wenshaoyang@zjnu.cn (W.Y.); \\ hchuanqi@foxmail.com (C.H.); lijie_zjnu@163.com (J.L.) \\ 2 Dalian National Laboratory for Clean Energy, Dalian Institute of Chemical Physics, Chinese Academy of \\ Sciences, Dalian 116023, China \\ 3 The State Key Laboratory of Catalysis, Dalian Institute of Chemical Physics, Chinese Academy of Sciences, \\ Dalian 116023, China \\ * Correspondence: yuantan2012@zjnu.edu.cn (Y.T.); dyj@dicp.ac.cn (Y.D.); \\ Tel.: +86-571-82257902 (Y.T.); +86-411-84379143 (Y.D.)
}

check for updates

Citation: Li, H.; Tan, Y.; Chen, X.; Yang, W.; Huang, C.; Li, J.; Ding, Y. Efficient Synthesis of Methyl Methacrylate by One Step Oxidative Esterification over Zn-Al-Mixed Oxides Supported Gold Nanocatalysts. Catalysts 2021, 11, 162. https:// doi.org/10.3390/catal11020162

Academic Editor: Werner Oberhauser Received: 18 December 2020

Accepted: 21 January 2021

Published: 25 January 2021

Publisher's Note: MDPI stays neutral with regard to jurisdictional claims in published maps and institutional affiliations.

Copyright: (c) 2021 by the authors. Licensee MDPI, Basel, Switzerland. This article is an open access article distributed under the terms and conditions of the Creative Commons Attribution (CC BY) license (https:// creativecommons.org/licenses/by/ $4.0 /)$.
Abstract: Methyl methacrylate (MMA) is an important monomer in fine chemicals. The synthesis of MMA by one-step oxidative esterification from methacrolein with methanol over a heterogeneous catalyst with high activity, selectivity and stability is highly desirable. Herein, Zn-Al-hydrotalcites (HTs)-supported atomically precise $\mathrm{Au}_{25}$ nanoclusters with different molar ratios of $\mathrm{Zn}^{2+} / \mathrm{Al}^{3+}$ were prepared and used as the precursors for this reaction. They exhibited good performances in comparison with the gold catalysts prepared by the deposition precipitation method. The structural and electronic properties were evaluated by various characterization technologies, including X-ray diffraction (XRD), high-resolution transmission electron microscopy (HRTEM), in situ diffuse reflectance infrared Fourier-transform spectroscopy (DRIFTS) of CO adsorption, X-ray photoelectron spectroscopy (XPS), and $\mathrm{CO}_{2}$ temperature-programmed desorption (TPD). The combined characterization results suggested that the adsorption property of gold and the basicity of the catalyst contributes to their high activities. Substrates extended experiments and stability tests implied the potential application of $\mathrm{Zn}$-Al-mixed oxides supported gold catalysts, which paves a new way for supported gold catalyst in the one-step oxidation esterification reaction.

Keywords: gold cluster; hydrotalcite; methacrolein; methyl methacrylate; oxidative esterification

\section{Introduction}

Methyl methacrylate (MMA) is an important monomer for the synthesis of polymethyl methacrylate (PMMA), which is widely used for producing acrylic plastic [1]. A recent analysis originated from the global MMA market indicated that the demand for MMA may reach $\$ 9.8$ billion by 2027 [2]. Thus, a noteworthy growth in MMA monomers will appear in the next several years. Traditionally, the dominant industrial process for the synthesis of MMA has been the acetone cyanohydrin $(\mathrm{ACH})$ route [3], in which acetone and hydrocyanic acid are used as the raw materials. At the same time, the $\mathrm{ACH}$ process involves environmentally unfriendly issues that employ strong sulfuric acid as a catalyst and inevitably generate ammonium bisulfate waste $[3,4]$.

Currently, isobutene (IB) oxidation routes that stem from isobutene and C4 ingredients for producing MMA are attracting great interest due to the economic and environmental preponderance $[5,6]$. In these processes, isobutene is first oxidized to methacrolein (MAL) and then oxidized to methacrylic acid (MAA), followed by esterification of MAA to MMA [5]. Instead, MAL could also react with methanol to form MMA by one-step oxidative esterification (Scheme 1) [6]. In view of energy efficiency and environmental 
cost, the direct oxidative esterification process is more attractive in comparison with the two-step method. However, it is still very challenging for the development of efficient and selective catalytic systems under moderate conditions by a one-step method $[7,8]$.

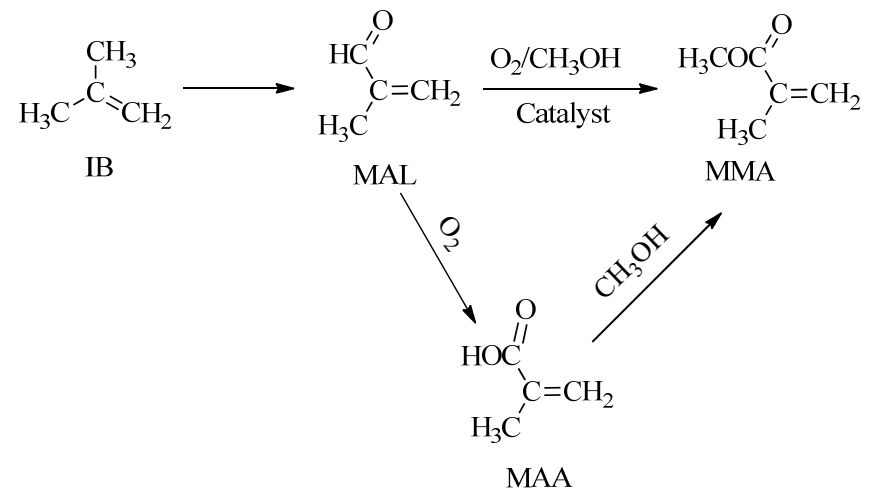

Scheme 1. Isobutene oxidation routes to produce methyl methacrylate (MMA).

Supported gold catalysts are generally believed to exhibit good performances in oxidation reactions under moderate conditions [9-14]. The special property enables it to be a potential candidate to replace traditional $\mathrm{Pd}$-based catalysts in one-step oxidative esterification [15-22]. Previously, K. Suzuki at Asahi Kasei developed a $\mathrm{SiO}_{2}-\mathrm{Al}_{2} \mathrm{O}_{3}-\mathrm{MgO}$ multiple oxides-supported $\mathrm{AuNiO}_{x}$ catalyst with core-shell structure [15]. The catalyst showed good performance for MAL to MMA, with the conversion of $\sim 60 \%$ and selectivity of $96-97 \%$. After this, Wang et al. observed good activity and selectivity over the $\mathrm{Au} / \mathrm{MgO}$ catalyst, which showed conversion of $98 \%$ and selectivity of $99 \%$, respectively [16]. Moreover, gold catalysts supported on different transition metal oxides and hydroxyapatite have been prepared in this reaction to evaluate the catalytic performances [17-22]. Their comparing results are shown in Table S1. Based on these results, the property of the support and/or the particle size of gold has been demonstrated to be crucial for one-step oxidative esterification $[16,17,21]$. The support with strong basic sites and the gold with a small average particle size are said to benefit the transformation of MAL to MMA [16,21]. However, although the activity and selectivity of supported gold catalysts exhibited great advantages to traditional Pd-based catalysts, the stability was among one of the big challenges.

Recently, layered double hydroxides (HTs) or hydrotalcite-type compounds, which have a general formula of $\left[\mathrm{M}_{1-\mathrm{x}}{ }^{2+} \mathrm{M}_{\mathrm{x}}{ }^{3+}(\mathrm{OH})_{2}\right]^{\mathrm{x}+} \cdot\left[\left(\mathrm{A}^{\mathrm{n}-}\right)_{\mathrm{x} / \mathrm{n}}\right] \cdot \mathrm{yH}_{2} \mathrm{O}$, have attracted great interest due to their high surface area, homogeneously dispersed metal atoms and acidbase properties [23-25]. Up to now, they have been utilized in a wide variety of oxidative reactions, such as the oxidation of benzyl alcohol [26], the oxidative steam reforming of methanol [27], the styrene epoxidation [28] and, etc. Previously, Zn-Al-mixed oxidesupported gold catalysts were demonstrated by us to display special catalytic performances in selective hydrogenation reactions [29-31]. The interaction between the gold and the support made it a great candidate for the synthesis of gold catalysts with controllable sizes [29,31]. Moreover, the inert activation for the vinyl group enables it a potential nominee for selective hydrogenation or oxidation reaction.

Herein, to synthesize the gold catalyst with homogeneous size, atomically precisely $\mathrm{Au}_{25}$ nanoclusters were preliminarily prepared to use as a precursor; $\mathrm{Zn}$-Al hydrotalcites with different $\mathrm{Zn}^{2+} / \mathrm{Al}^{3+}$ molar ratios were used as the precursors of supports. The catalysts were applied for one-step oxidative esterification of methacrolein with methanol to the synthesis of MMA. In comparison with the catalytic performances of gold catalysts prepared by the deposition precipitation method, the $\mathrm{Au}_{25} / \mathrm{Zn}_{\mathrm{x}} \mathrm{Al}-400(\mathrm{x}=3,2,1)$ catalysts exhibited comparable better activity. $\mathrm{N}_{2}$-physical adsorption-desorption, $\mathrm{X}$-ray diffraction (XRD), transmission electron microscopy (TEM), in situ diffuse reflectance infrared Fouriertransform spectroscopy (DRIFTS) of CO adsorption, X-ray photoelectron spectroscopy (XPS) and $\mathrm{CO}_{2}$ temperature-programmed desorption (TPD) were utilized to characterize 
the structural and electronic properties of the catalysts, from which the relationship about the structure and catalytic performances were reasonably revealed.

\section{Results and Discussion}

\subsection{Catalytic Performances}

$\mathrm{Zn}$-Al-HTs with different molar ratios supported gold nanoclusters were used as the precursors of the catalysts. Their catalytic performances were successively investigated in one-step oxidative esterification of MAL with methanol (MeOH) for the synthesis of MMA (Scheme 2).

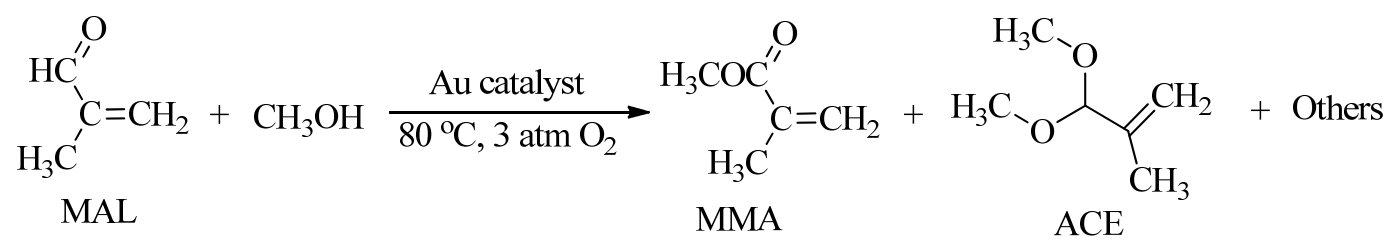

Scheme 2. Reaction pathway of methacrolein (MAL) with MeOH to form MMA.

From the results, the supported gold catalyst with $\mathrm{Zn}^{2+} / \mathrm{Al}^{3+}$ molar ratio of 3 showed conversion of $84.9 \%$ and selectivity of $95.1 \%$ as the reaction was conducted at $353 \mathrm{~K}$ and $3 \mathrm{~atm} \mathrm{O}_{2}$ for $2 \mathrm{~h}$. (Table 1, entry 1). When the $\mathrm{Zn}^{2+} / \mathrm{Al}^{3+}$ ratio decreased from 3 to 2, the conversion of MAL increased to $93.1 \%$, with the selectivity of MMA maintained at $94.8 \%$ (Table 1, entry 2). Further decreased the $\mathrm{Zn}^{2+} / \mathrm{Al}^{3+}$ ratio to 1 , both the activity and selectivity reduced, with the value being $90 \%$ and $92 \%$, respectively (Table 1 , entry 3 ). To be noted, although the final conversion of MAL was the highest over the $\mathrm{Au}_{25} / \mathrm{Zn}_{2} \mathrm{Al}-400$ catalyst, the turnover frequency (TOF) based on total gold metals was slightly lower than that of the $\mathrm{Au}_{25} / \mathrm{Zn}_{3} \mathrm{Al}-400$ and $\mathrm{Au}_{25} / \mathrm{Zn}_{1} \mathrm{Al}-400$ catalysts. The reason may be originated from the influence of the $\mathrm{Zn}^{2+} / \mathrm{Al}^{3+}$ molar ratio on the adsorption of reactant, which leads to the difference of initial reaction rate to final reaction rate.

Table 1. Catalytic activities of MAL with $\mathrm{MeOH}$ to form MMA over supported gold catalysts.

\begin{tabular}{ccccccc}
\hline \multirow{2}{*}{ Entry } & Catalysts & Conversion (\%) & \multicolumn{3}{c}{ Selectivity (\%) } & \\
\cline { 4 - 6 } & & & MMA & ACE & Others & \\
\hline 1 & $\mathrm{Au}_{25} / \mathrm{Zn}_{3} \mathrm{Al}-400$ & 84.9 & 95.1 & 0.7 & 4.2 & 1734 \\
2 & $\mathrm{Au}_{25} / \mathrm{Zn}_{2} \mathrm{Al}-400$ & 93.1 & 94.8 & 0.8 & 4.4 & 1626 \\
3 & $\mathrm{Au}_{25} / \mathrm{Zn}_{1} \mathrm{Al}-400$ & 90.1 & 92.0 & 0.5 & 7.5 & 1675 \\
4 & $\mathrm{Au} / \mathrm{Zn}_{2} \mathrm{Al}-400$ & 57.1 & 94.1 & 3.4 & 2.5 & 684 \\
5 & $\mathrm{Zn}_{3} \mathrm{Al}-400$ & 6.4 & 0 & 99.0 & - & - \\
6 & $\mathrm{Zn}_{2} \mathrm{Al}-400$ & 13.2 & 0 & 94.8 & - & - \\
7 & $\mathrm{Zn}_{1} \mathrm{Al}-400$ & 16.9 & 0 & 91.0 & - & - \\
8 & $\mathrm{Blank}$ & 0 & - & - & - & - \\
\hline
\end{tabular}

Reaction conditions: $\mathrm{MAL} / \mathrm{MeOH}=1 / 23$ (molar ratio), $\mathrm{V}(\mathrm{MeOH})=4.5 \mathrm{~mL}$, Catalyst: $0.1 \mathrm{~g}$ (Au: $0.1 \mathrm{~mol} \%$ ) $\mathrm{T}=353 \mathrm{~K}, \mathrm{P}_{\mathrm{O} 2}=3 \mathrm{~atm}, \mathrm{t}=2 \mathrm{~h} .{ }^{\mathrm{a}}$ Conversion and selectivity were analyzed by gas chromatography; ${ }^{\mathrm{b}}$ turnover frequency (TOF) of different catalysts was measured by moles of converted MAL per mole of gold per hour, with the conversion of MAL below $20 \%$.

Hence, to study the evolution of the product distribution during the reaction process of MAL with $\mathrm{MeOH}$, the dynamic experiments were carried out on the $\mathrm{Au}_{25} / \mathrm{Zn}_{\mathrm{x}} \mathrm{Al}-400$ catalysts with various $\mathrm{Zn}^{2+} / \mathrm{Al}^{3+}$ molar ratios. The yields of MAL and products with reaction time were plotted in Figure 1a-c. From the results, the product distributions over the three catalysts were similar within the reaction progress. After prolonging the reaction time, MMA was formed as the sacrifice of MAL. In the meantime, few acetals and byproducts appeared via the reaction of MAL and impurity aldehyde with $\mathrm{MeOH}$ (Figure S1). The reaction rates over the three catalysts decreased gradually from beginning to end, suggesting the dependence of activity on the concentration of the reactant. However, the selectivity of MMA could be well maintained at above $90 \%$ despite the various $\mathrm{Zn}^{2+} / \mathrm{Al}^{3+}$ ratios. 

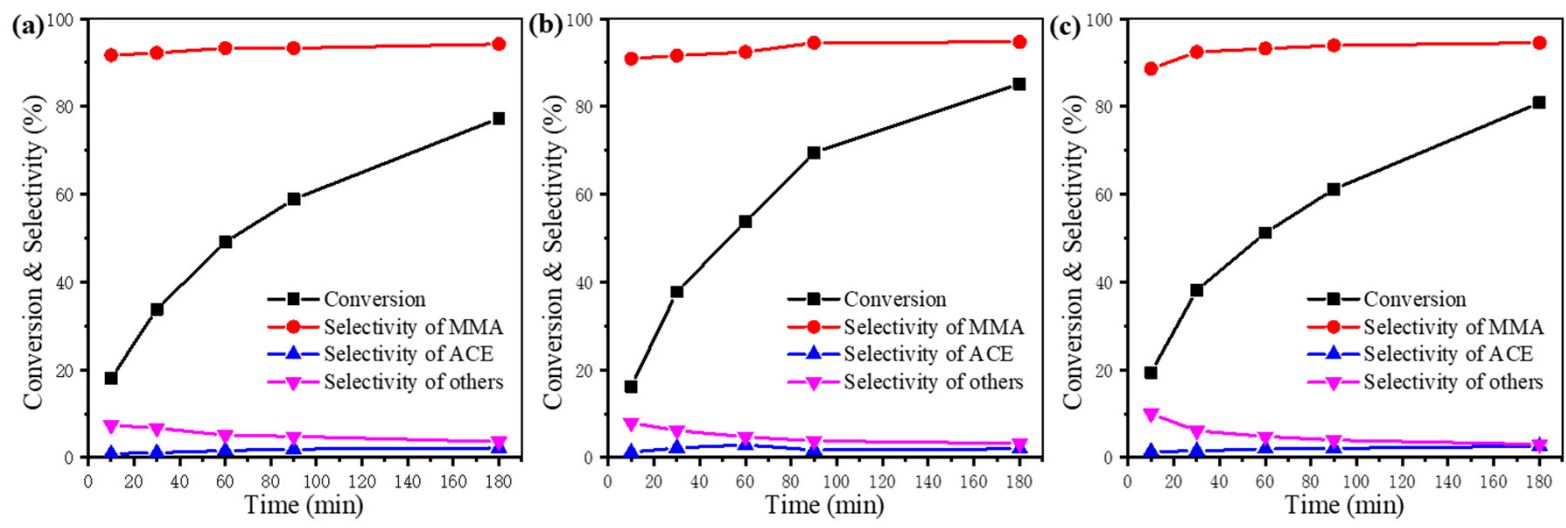

Figure 1. The products distributions of reaction with time courses over the (a) $\mathrm{Au}_{25} / \mathrm{Zn}_{3} \mathrm{Al}-400$; (b) $\mathrm{Au}_{25} / \mathrm{Zn}_{2} \mathrm{Al}-400$ and (c) $\mathrm{Au}_{25} / \mathrm{Zn}_{1} \mathrm{Al}-400$ catalysts. Reaction conditions: $\mathrm{MAL} / \mathrm{MeOH}=1 / 23$ (molar ratio), catalyst: $0.05 \mathrm{~g}$, temperature: $353 \mathrm{~K}$, $\mathrm{O}_{2}$ pressure: $3 \mathrm{~atm}$.

Under the same conditions, the supported gold catalysts prepared by the traditional deposition-precipitation (DP) method were synthesized for this reaction to make a comparison. The results are shown in Table 1, entry 4, with $\mathrm{Zn}^{2+} / \mathrm{Al}^{3+}$ molar ratios of 2 . As seen, the conversion of MAL over the $\mathrm{Au} / \mathrm{Zn}_{2} \mathrm{Al}-400$ catalyst was $57.1 \%$, which fell much lower than that of the $\mathrm{Au}_{25} / \mathrm{Zn}_{x} \mathrm{Al}-400$. Simultaneously, the TOF value was several times lower than that of the $\mathrm{Au}_{25} / \mathrm{Zn}_{x} \mathrm{Al}-400$. It suggested that the utilization of $\mathrm{Au}_{25}$ nanoclusters as the precursor of gold greatly improves the activity. Following characterizations about the geometric and electronic structure of the gold catalysts were provided to reveal the structure-activity relationship.

Moreover, to disclose the effect of support for this reaction, the heat-treated $\mathrm{Zn}_{x} \mathrm{Al}-\mathrm{HTs}$ at $400{ }^{\circ} \mathrm{C}$ were also applied in this reaction under the same conditions (Table 1, entry 5-7). As seen, although $6.4 \%, 13.2 \%$ and $16.9 \%$ of the MAL conversions were observed over the $\mathrm{Zn}_{3} \mathrm{Al}-400, \mathrm{Zn}_{2} \mathrm{Al}-400$ and $\mathrm{Zn}_{1} \mathrm{Al}-400$ samples, no target product of MMA appeared in the system. It indicated the significant role of gold species towards one-step oxidative esterification of MAL to MMA. Moreover, to eliminate the effect of device deviation, the blank experiment with no catalysts or supports was conducted at the same condition (Table 1, entry 8). Almost no transformation of MAL to MMA could be observed, indicating the reaction between MAL and $\mathrm{MeOH}$ indeed occurred on our catalysts. To be noted, when compared the catalytic performance of $\mathrm{Au}_{25} / \mathrm{Zn}_{2} \mathrm{Al}-400$ with the other catalysts in previous work, the activity and selectivity of our catalysts were among one the best-performing catalysts under similar conditions. Such results are shown in Table S1.

\subsection{Structure of the Catalysts}

The chemical analysis of $\mathrm{Zn}$-Al-mixed oxides supported gold catalysts were measured by inductively coupled plasma atomic emission spectroscopy (ICP-AES). The loadings of gold on the $\mathrm{Au}_{25} / \mathrm{Zn}_{3} \mathrm{Al}-400, \mathrm{Au}_{25} / \mathrm{Zn}_{2} \mathrm{Al}-400, \mathrm{Au}_{25} / \mathrm{Zn}_{1} \mathrm{Al}-400$ and $\mathrm{Au} / \mathrm{Zn}_{2} \mathrm{Al}-400$ catalysts after heat treatment were 1.3, 1.2, 1.3 and $1.3 \mathrm{wt} \%$, respectively, which agreed well with the nominal values. The actual molar ratios of $\mathrm{Zn}^{2+} / \mathrm{Al}^{3+}$ were 3.3, 2.4 and 1.2, respectively, with the content of $\mathrm{Zn}^{2+}$ and $\mathrm{Al}^{3+}$ of $21-32 \mathrm{wt} \%$ and $3.3-7.4 \mathrm{wt} \%$, respectively (Table S2). The pore structure parameters such as the specific surface area, the pore volume and pore width were evaluated by the $\mathrm{N}_{2}$-physical adsorption-desorption test (Table 2). The isotherms were exhibited in Figure S2. Based on the classification of IUPAC [32,33], the above catalysts exhibited typical IV type isotherms with obviously H3-type hysteresis loop, suggesting that the mesoporous structures existed in the above catalysts, which may result from the collapse of hydrotalcites structure after heat treatment. 
Table 2. Textural properties of Zn-Al-mixed oxides supported gold nanoclusters.

\begin{tabular}{|c|c|c|c|c|c|c|c|}
\hline Entry & Catalyst & $\begin{array}{c}\text { Loadings of } \\
\text { Gold (wt \%) }{ }^{\text {a }}\end{array}$ & $\begin{array}{l}\text { Surface Area } \\
\left(\mathrm{m}^{2} / \mathrm{g}\right)^{\mathrm{b}}\end{array}$ & $\begin{array}{l}\text { Pore Volume } \\
\left(\mathrm{cm}^{3} / \mathrm{g}\right)^{\mathrm{c}}\end{array}$ & $\begin{array}{c}\text { Half Pore } \\
\text { Width }(\mathrm{nm})^{\mathrm{d}}\end{array}$ & $\begin{array}{l}\text { Particle Size } \\
\text { of Gold (nm) e }\end{array}$ & $\begin{array}{c}\text { Total Basicity } \\
\left(\mu \mathrm{mol} \mathrm{CO} \mathrm{CO}_{2} / \mathrm{g}_{\text {cat }}\right) \mathrm{f}\end{array}$ \\
\hline 1 & $\mathrm{Au}_{25} / \mathrm{Zn}_{3} \mathrm{Al}-400$ & 1.27 & 49.1 & 0.24 & 1.71 & 2.8 & 640 \\
\hline 2 & $\mathrm{Au}_{25} / \mathrm{Zn}_{2} \mathrm{Al}-400$ & 1.18 & 60.5 & 0.14 & 1.53 & 2.5 & 500 \\
\hline 3 & $\mathrm{Au}_{25} / \mathrm{Zn}_{1} \mathrm{Al}-400$ & 1.32 & 80.9 & 0.27 & 1.71 & 2.5 & 430 \\
\hline 4 & $\mathrm{Au} / \mathrm{Zn}_{2} \mathrm{Al}-400$ & 1.32 & 71.0 & 0.08 & 1.90 & 2.8 & 540 \\
\hline
\end{tabular}

${ }^{a}$ The actual loadings of gold were evaluated by inductively coupled plasma atomic emission spectroscopy (ICP-AES) measurement. ${ }^{b}$ Surface area was calculated from the Brunauer-Emmet-Teller (BET) equation at $\mathrm{P} / \mathrm{P}_{0}$ range of $0.05-0.3{ }^{\mathrm{c}}$ Total pore volume was calculated at $\mathrm{P} / \mathrm{P}_{0}=0.98$. ${ }^{\mathrm{d}}$ Pore width was calculated from the adsorption branch of the isotherm- $\mathrm{BJH}$. ${ }^{\mathrm{e}}$ The mean particle sizes of gold were calculated from TEM measurements. ${ }^{\mathrm{f}}$ Total basicity was calculated from $\mathrm{CO}_{2}-\mathrm{TPD}$.

The crystallographic phases of the catalysts before and after calcination were analyzed by powder XRD. The patterns are shown in Figure 2. Before the thermal treatment, all of the catalysts exhibited the characteristic reflections of the hydrotalcite lamellar structure with intense diffraction peaks at $11.7^{\circ}, 23.6^{\circ}, 34.6^{\circ}, 39.7^{\circ}, 46.8^{\circ}, 60.4^{\circ}$ and $61.8^{\circ}$ (Figure 2a). These peaks could be assigned to (003), (006), (012), (015), (018), (110) and (113) planes of standard zinc-aluminum hydrotalcite (JCPDS NO. 00-048-1023). After calcination, the lamellar structure of hydrotalcites went into collapse, with the formation of $\mathrm{Zn}$-Almixed oxides. The XRD patterns of the samples after heat treatment at $400{ }^{\circ} \mathrm{C}$ are shown in Figure $2 \mathrm{~b}$, in which obvious sharp peaks corresponding to reflections of $\mathrm{ZnO}$ phase (JCPDS NO. 01-089-0510) were observed, with the peaks located at around $32.1^{\circ}, 34.6^{\circ}, 36.5^{\circ}, 47.6^{\circ}$, $56.8^{\circ}$ and $62.7^{\circ}$. It demonstrated that $\mathrm{Zn}$ and $\mathrm{Al}$ atoms were homogeneously distributed in the framework of the catalysts. Noteworthy, no diffraction peaks ascribed as face-centered cubic gold were observed in all of the catalysts, perhaps due to the small particle sizes or low concentration of $\mathrm{Au}$.
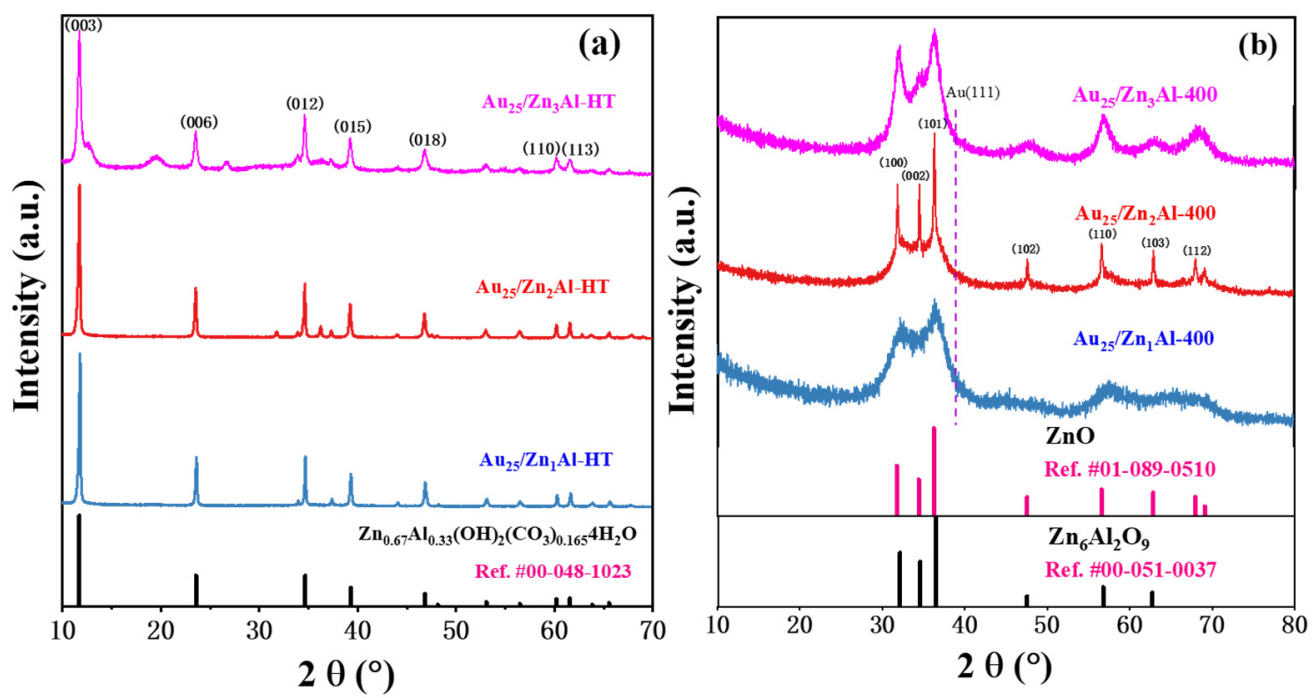

Figure 2. XRD patterns of Zn-Al-HTs supported gold nanoclusters before (a) and after (b) heat treatment.

In order to examine the particle sizes and lattice parameters of gold, TEM and HRTEM were performed on the $\mathrm{Au}_{25} / \mathrm{Zn}_{\mathrm{x}} \mathrm{Al}-400(\mathrm{x}=3,2,1)$ and $\mathrm{Au} / \mathrm{Zn}_{2} \mathrm{Al}-400$ (DP) catalysts (Figure 3). More than 200 nanoparticles in representative regions were included to count the average particle sizes. As shown from TEM images, all of the gold particles after thermal treatment were uniformly dispersed on the catalysts, with similar particle sizes of $2.8 \pm 0.7 \mathrm{~nm}$ (Figure $3 \mathrm{a}_{1}$ ), $2.5 \pm 0.8 \mathrm{~nm}$ (Figure $3 \mathrm{~b}_{1}$ ), $2.5 \pm 0.7 \mathrm{~nm}$ (Figure $3 \mathrm{c}_{1}$ ) and $2.8 \pm 0.9 \mathrm{~nm}$ (Figure $3 \mathrm{~d}_{1}$ ) over the $\mathrm{Au}_{25} / \mathrm{Zn}_{3} \mathrm{Al}-400, \mathrm{Au}_{25} / \mathrm{Zn}_{2} \mathrm{Al}-400, \mathrm{Au}_{25} / \mathrm{Zn}_{1} \mathrm{Al}-400$ and $\mathrm{Au} / \mathrm{Zn}_{2} \mathrm{Al}-400$ catalysts, respectively. Moreover, the gold particles with the shape of hexagon, sphere or ellipsoid could be observed, with clear boundaries between gold and 
supports. The interplanar spacing of $2.42 \AA, 2.60 \AA$ and $2.80 \AA$ corresponded to (101), (100) and (002) lattice fringes of the supports that were consistent with the XRD results.
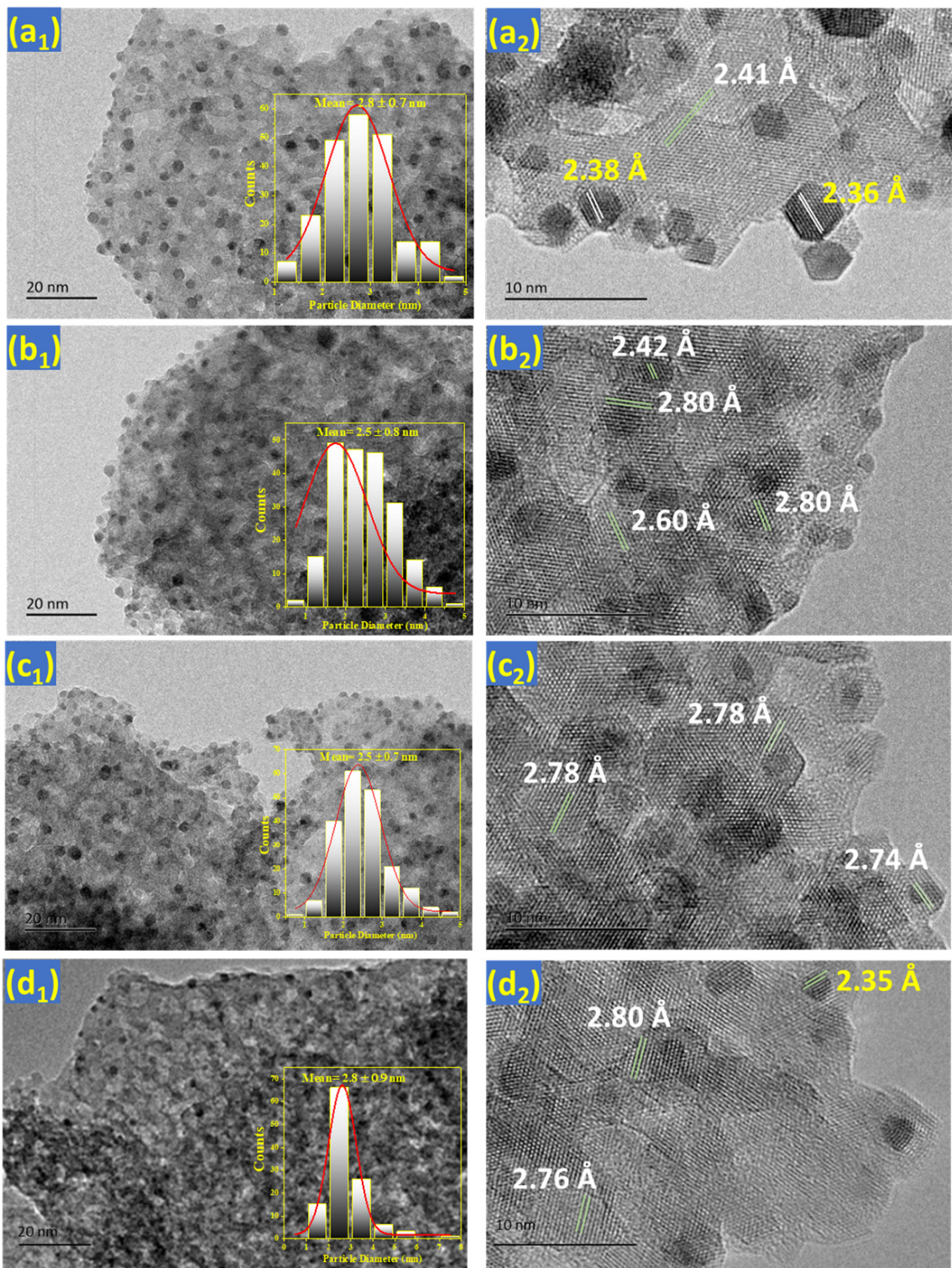

Figure 3. TEM $\left(\mathrm{a}_{1}-\mathrm{d}_{1}\right)$ and HRTEM $\left(\mathrm{a}_{2}-\mathrm{d}_{2}\right)$ images of supported gold catalysts: $\left(\mathbf{a}_{1-2}\right) \mathrm{Au}_{25} / \mathrm{Zn}_{3} \mathrm{Al}-400$; (b $\left.\mathbf{b}_{1-2}\right) \mathrm{Au}_{25} / \mathrm{Zn}_{2} \mathrm{Al}-400 ;\left(\mathbf{c}_{1-2}\right) \mathrm{Au}_{25} / \mathrm{Zn}_{1} \mathrm{Al}-400 ;\left(\mathbf{d}_{1-2}\right) \mathrm{Au} / \mathrm{Zn}_{2} \mathrm{Al}-400$ (deposition-precipitation (DP)).

\subsection{Electronic Property of the Catalyst}

The in situ DRIFTS of CO adsorption was conducted to characterize the state of gold and active species on the surface of the $\mathrm{Au}_{25} / \mathrm{Zn}_{x} \mathrm{Al}-400$ and $\mathrm{Au} / \mathrm{Zn}_{2} \mathrm{Al}-400$ catalysts (Figure 4). The double peaks at 2119 and $2168 \mathrm{~cm}^{-1}$ could be ascribed to the adsorption of the gas phase $\mathrm{CO}$, which disappeared gradually with the purging of helium. An obvious band at around $2102-2105 \mathrm{~cm}^{-1}$ was presented in the $\mathrm{Au}_{25} / \mathrm{Zn}_{x} \mathrm{Al}-400$ catalysts (Figure $4 \mathrm{a}-\mathrm{c}$ ). It could be ascribed to the CO molecule adsorbed on metallic gold [34]. Whereas on the $\mathrm{Au} / \mathrm{Zn}_{2} \mathrm{Al}-400$ catalyst, no adsorption peak of $\mathrm{CO}$ was observed in the spectra except for the gaseous $\mathrm{CO}$, indicating the adsorption of $\mathrm{CO}$ was very weak on the $\mathrm{Au} / \mathrm{Zn}_{2} \mathrm{Al}-400$ catalyst (Figure $4 \mathrm{~d}$ ). That may result in the poor activity of Au/ $\mathrm{Zn}_{2} \mathrm{Al}-400$ in oxidation esterification than that of the $\mathrm{Au}_{25} / \mathrm{Zn}_{x} \mathrm{Al}-400(\mathrm{x}=3,2,1)$ catalysts. 

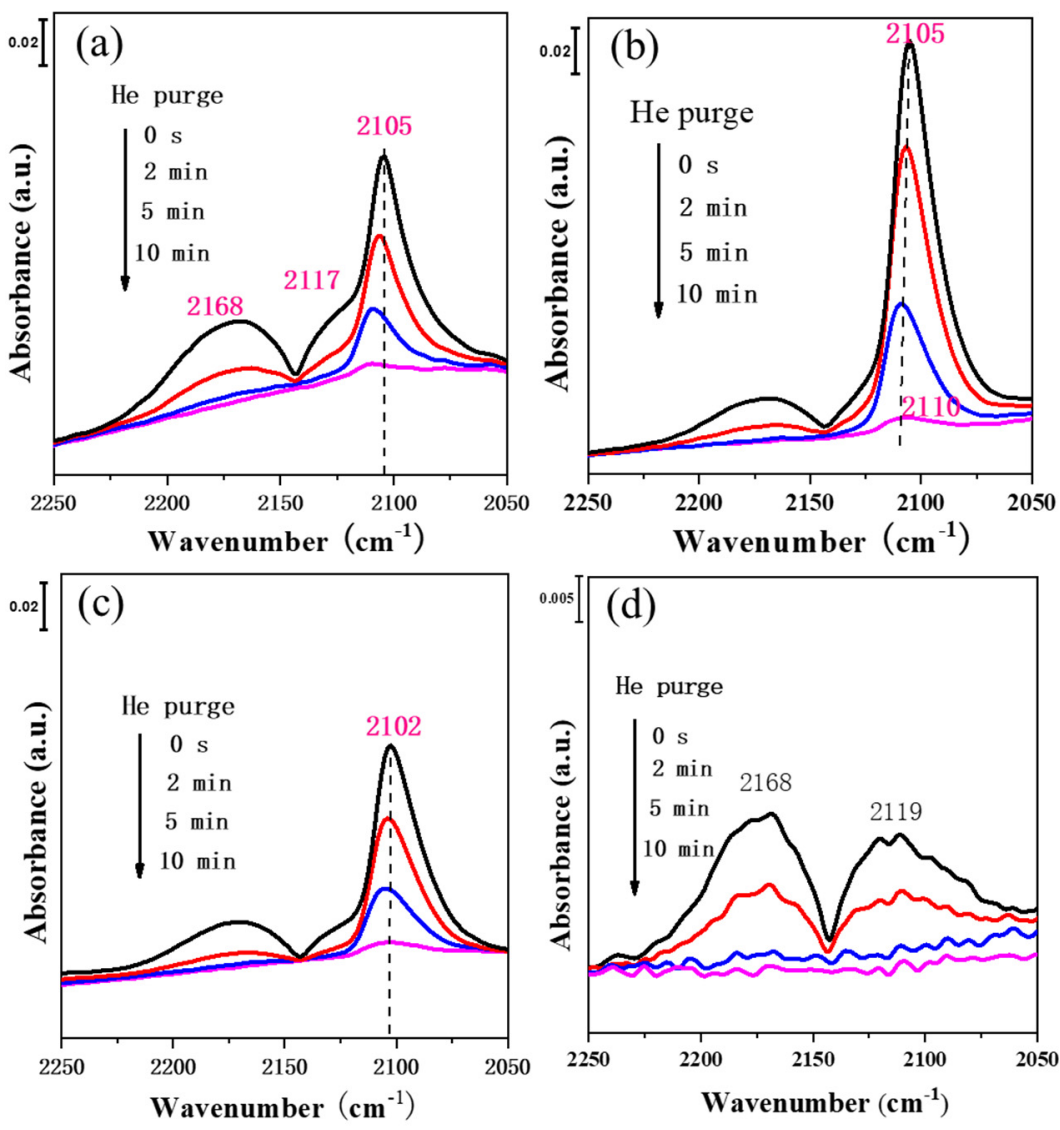

Figure 4. In situ diffuse reflectance infrared Fourier-transform spectroscopy of $\mathrm{CO}$ adsorption (CO-DRIFT) spectra of supported gold catalysts: (a) $\mathrm{Au}_{25} / \mathrm{Zn}_{3} \mathrm{Al}-400$; (b) $\mathrm{Au}_{25} / \mathrm{Zn}_{2} \mathrm{Al}-400$; (c) $\mathrm{Au}_{25} / \mathrm{Zn}_{1} \mathrm{Al}-400 ;(\mathrm{d}) \mathrm{Au} / \mathrm{Zn}_{2} \mathrm{Al}-400$ (DP).

The valence state of gold was also provided by X-ray photoelectron spectra (XPS). Figure 5 displayed a wide spectrum of the core levels of $\mathrm{Au}, \mathrm{Zn}, \mathrm{Al}, \mathrm{C}, \mathrm{O}$ (Figure $5 \mathrm{a}$ ) and the high-resolution XPS spectra of Au 4f, C 1s, Zn 2p, Al 2p and O 1s on the $\mathrm{Au}_{25} / \mathrm{Zn}_{x} \mathrm{Al}-400$ catalysts. Although part of the peak of Au $4 \mathrm{f}_{5 / 2}$ was overlapped by the signal of $\mathrm{Zn} 3 p$ (Figure $5 b$ ), the branches of $A u 4 f_{7 / 2}$ could be deconvoluted from the peak. Obviously, the metallic gold $\left(\mathrm{Au}^{0}\right)$ dominates the surface of gold species, with the binding energy at around $83.5 \mathrm{eV}$, which agreed well with the in situ CO DRIFT spectra. Moreover, three deconvoluted peaks located at about 288.3, 285.6 and $284.0 \mathrm{eV}$ were presented in C 1s XPS spectra (Figure 5c), which could be assigned to the $\mathrm{C}=\mathrm{O}, \mathrm{C}-\mathrm{O}$ and $\mathrm{C}-\mathrm{C}$ bonds [35]. It indicated there were still carbonate on the catalysts even after high-temperature calcination at $400{ }^{\circ} \mathrm{C}$. Additionally, $\mathrm{O} 1 \mathrm{~s}$ XPS fitting results displayed the existence of $\mathrm{O}^{2-}, \mathrm{O}-\mathrm{H}$ and $\mathrm{C}=\mathrm{O}$ species [36,37], which are named $\mathrm{O}_{\alpha}, \mathrm{O}_{\beta}$ and $\mathrm{O}_{\gamma}$, respectively (Figure 5f). The lattice oxygen of $\mathrm{O}_{\alpha}$ bounded to the metal cation of $\mathrm{Zn}^{2+}$ and $\mathrm{Al}^{3+}$, which was supported by $\mathrm{Zn}$ $2 p$ (Figure $5 \mathrm{~d}$ ) and $\mathrm{Al} 2 \mathrm{p}$ (Figure 5e) XPS spectra. To be noted, with decreasing of $\mathrm{Zn}^{2+} / \mathrm{Al}^{3+}$ molar ratios, the valence state of $\mathrm{Zn}, \mathrm{Al}, \mathrm{O}$ species varied correspondingly, indicating the slight variation of the structure over the $\mathrm{Zn}-\mathrm{Al}$ mixed oxides. Moreover, the oxygen in the form of a hydroxyl group $\left(\mathrm{O}_{\beta}\right)$ provided some basic sites of the catalysts that may promote the reaction since the abundance of previous works highlights the effect of basicity for catalytical performances $[16,19,38]$. 

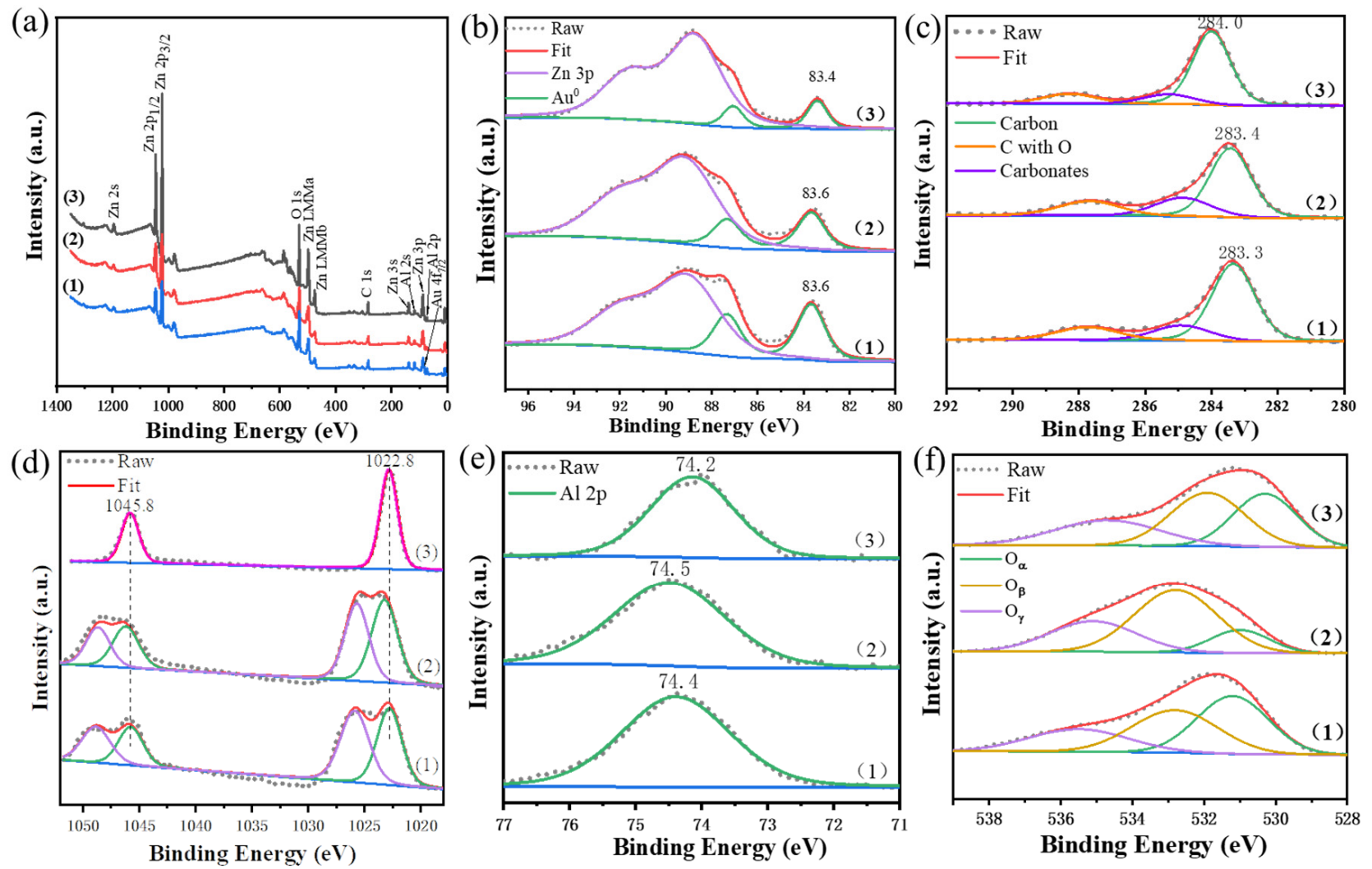

Figure 5. (a) XPS wide spectra and (b) Au 4f, (c) C 1s, (d) Zn 2p, (e) Al 2p (f) O 1s of XPS spectra over the Au $\mathrm{Au}_{25} / \mathrm{Zn}_{\mathrm{x}} \mathrm{Al}-400$ catalyst: (1) $\mathrm{Zn}^{2+} / \mathrm{Al}^{3+}=1$; (2) $\mathrm{Zn}^{2+} / \mathrm{Al}^{3+}=2$; (3) $\mathrm{Zn}^{2+} / \mathrm{Al}^{3+}=3$.

\subsection{The Basic Property of the Catalyst}

Previously, several groups have presented the significance of basicity towards oxidative esterification of MAL with methanol $[16,19,38]$. It was said that the catalysts with a large density of basic sites could accelerate the formation of hemiacetal intermediate, thus, contribute to the formation of MMA [16,38]. To analyze the basicity of the supported gold catalyst, $\mathrm{CO}_{2}$ temperature-programmed desorption (TPD) was subsequently employed on the $\mathrm{Au}_{25} / \mathrm{Zn}_{x} \mathrm{Al}-400$ and $\mathrm{Au} / \mathrm{Zn}_{2} \mathrm{Al}-400$ catalysts. The total basicity of the catalysts ranged from $430-640 \mu \mathrm{mol} / \mathrm{g}$, which is shown in Table 2. The fitted desorption curves according to $\mathrm{CO}_{2}$ desorption temperature were then displayed in Figure 6. From the results, all of the catalysts exhibited obvious bands below $250^{\circ} \mathrm{C}$ and big bands from 350 to $900^{\circ} \mathrm{C}$. The peak below $250^{\circ} \mathrm{C}$ could be assigned to weak basic sites of the catalysts $[17,21]$. However, the desorption peak of $\mathrm{CO}_{2}$ at the higher temperature would have resulted from the medium-strength basic sites $\left(250-470{ }^{\circ} \mathrm{C}\right)$, strong basic sites $\left(470-650^{\circ} \mathrm{C}\right)$ and super strong basic sites (above $650^{\circ} \mathrm{C}$ ) [21,39]. Through quantitative analysis of the basic sites, the gold catalysts supported on $\mathrm{Zn}_{2} \mathrm{Al}-400$ possess more strong basic sites $\left(470-650{ }^{\circ} \mathrm{C}\right)$ than that on the $\mathrm{Zn}_{3} \mathrm{Al}-400$ and $\mathrm{Zn}_{1} \mathrm{Al}-400$. While using $\mathrm{Au}_{25}$ clusters as the precursor of gold, more super-strong basic sites (above $650^{\circ} \mathrm{C}$ ) were observed in $\mathrm{Au}_{25} / \mathrm{Zn}_{x} \mathrm{Al}-400$ catalysts, which might be connected with their good catalytic performances. Moreover, to exclude the influence of decomposition of the residual hydrotalcites on the results of $\mathrm{CO}_{2}-$ $\mathrm{TPD}$, the comparison experiments were conducted on $\mathrm{Au}_{25} / \mathrm{Zn}_{x} \mathrm{Al}-400$ and $\mathrm{Au} / \mathrm{ZnAl}-400$ catalysts without adsorption of $\mathrm{CO}_{2}$, which showed a clear absence of $\mathrm{CO}_{2}$ desorption peak by acquiring the TCD and MS signal simultaneously (Figure S3). 


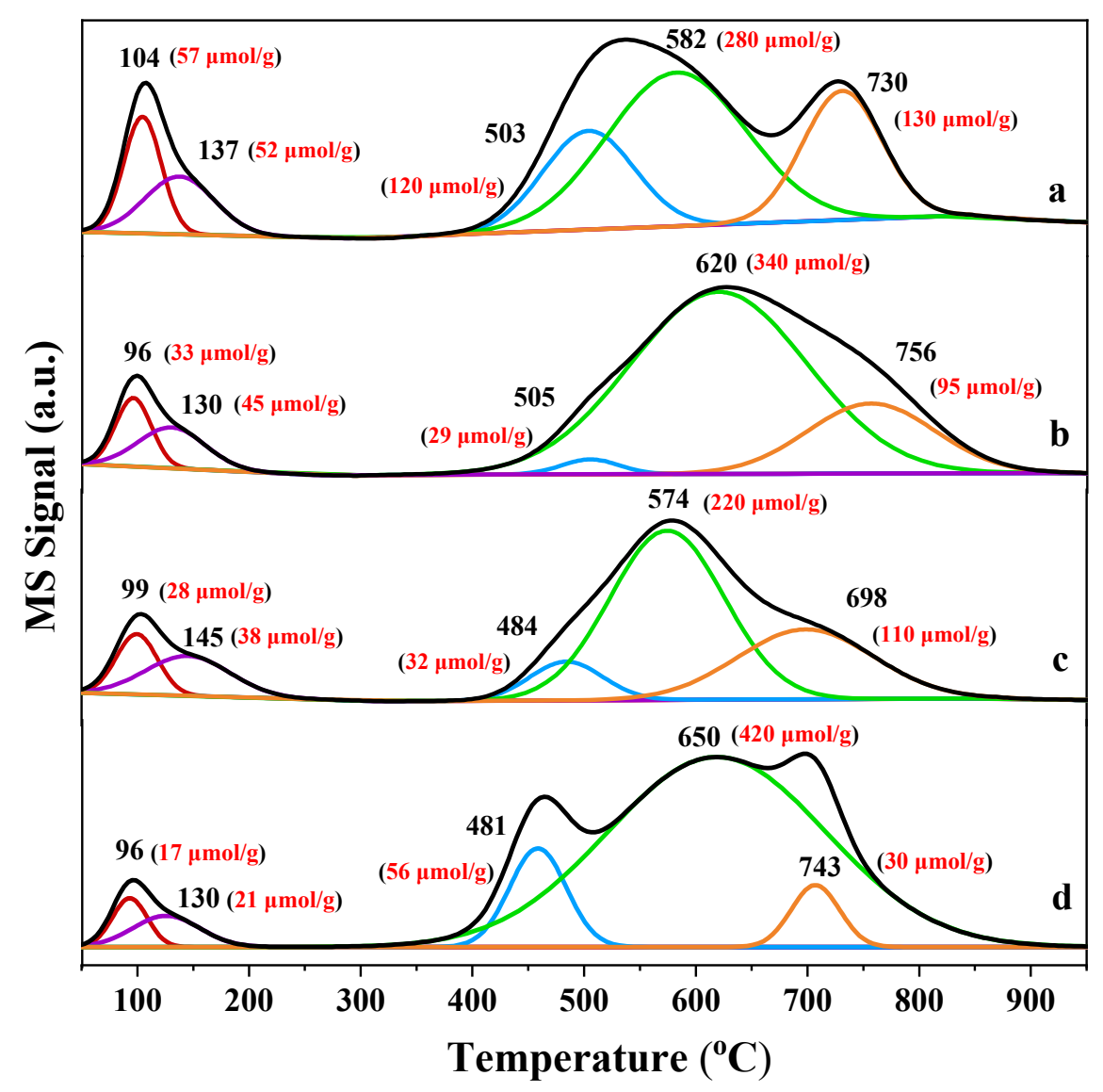

Figure 6. $\mathrm{CO}_{2}-\mathrm{TPD}$ of supported gold catalysts: (a) $\mathrm{Au}_{25} / \mathrm{Zn}_{3} \mathrm{Al}-400$; (b) $\mathrm{Au}_{25} / \mathrm{Zn}_{2} \mathrm{Al}-400$; (c) $\mathrm{Au}_{25} / \mathrm{Zn}_{1} \mathrm{Al}-400 ;(\mathrm{d}) \mathrm{Au} / \mathrm{Zn}_{2} \mathrm{Al}-400$.

\subsection{The Active Sites and Reaction Mechanism}

According to the catalytic performances on supported gold catalysts and calcined supports (Table 1), the active species were supposed to locate at the interface of gold particles and the supports, since the support itself was very hard to activate oxygen and transform the MAL to MMA (Table 1, entry 5-7). Moreover, the small gold particles were generally supposed to benefit the catalytic activity due to the abundant uncoordinated gold species over small gold particles [40,41]. On account of the XRD and TEM results, the average particle size of gold on the $\mathrm{Au} / \mathrm{Zn}_{2} \mathrm{Al}-400$ catalyst $(\sim 2.8 \mathrm{~nm}$, Figure $3 \mathrm{~d}$ ) was close to that of the $\mathrm{Au}_{25} / \mathrm{Zn}_{2} \mathrm{Al}-400$ ( 2.5 nm, Figure 3b), while the activity of it decreased dramatically from $93.1 \%$ (Table 1 , entry 2 ) to $57.1 \%$ (Table 1 , entry 4 ), and the TOF value reduced from $1626 \mathrm{~h}^{-1}$ to $684 \mathrm{~h}^{-1}$. Thus, the decreased activity might not be attributed merely to the size of gold.

Further characterization of the valence state of gold and the adsorption property of the catalysts were conducted by XPS and in situ CO DRIFT spectra. As shown in Figure 4, a strong adsorption peak of $\mathrm{CO}$ was observed on metallic gold over the $\mathrm{Au}_{25} / \mathrm{Zn}_{x} \mathrm{Al}-400$ catalyst (Figure $4 \mathrm{a}-\mathrm{c}$ ), while no adsorption band of $\mathrm{CO}$ could be found on the DP-methodprepared $\mathrm{Au} / \mathrm{Zn}_{2} \mathrm{Al}-400$ catalyst (Figure $4 \mathrm{~d}$ ). That is, the poor adsorption behavior of the $\mathrm{Au} / \mathrm{Zn}_{2} \mathrm{Al}-400$ catalyst is very different from that of the $\mathrm{Au}_{25} / \mathrm{Zn}_{x} \mathrm{Al}-400$, thus, lead to its poor activity. Moreover, $\mathrm{CO}_{2}-\mathrm{TPD}$ results indicated more super-strong basic sites existed in $\mathrm{Au}_{25} / \mathrm{Zn}_{x} \mathrm{Al}-400$ catalysts than that in $\mathrm{Au} / \mathrm{Zn}_{2} \mathrm{Al}-400$ (Figure 6), which may facilitate the transformation of MAL to hemiacetal intermediate. Further characterization about the intrinsic origin of the performance was still needed to make it clear. In contrast, the thiolate-protected gold clusters were demonstrated useful as the precursor of gold in preparation of the good-performing gold catalysts with controllable sizes. 
On the supported gold catalysts, the reaction mechanism for the oxidative esterification of MAL to MMA in the presence of molecular oxygen was generally involved with a two-step mechanism in the earlier study $[17,38,42]$. Based on this, herein, a postulated pathway over the $\mathrm{Au}_{25} / \mathrm{Zn}_{x} \mathrm{Al}-400$ catalyst is proposed in detail in the combination of the characterization results and catalytic performances (Scheme 3). In the pathway, oxygen and methanol molecule was first approaching the interface and then interacted with gold particles and basic sites to form the adsorbed atomic oxygen and methoxy. After this, the nucleophilic attack of methoxy to the carbon of methyl acrolein forms the surface hemiacetal intermediate. Moreover, finally, with the assistant of atomic oxygen, the hemiacetal intermediate transforms to the target ester via $\beta-\mathrm{H}$ elimination. The acetal appeared as the byproduct, indicating the competing reaction of hemiacetal intermediate attacked by methoxy and adsorbed oxygen. That revealed the selectivity of MMA was probably dependent on the dissociation of oxygen on well-dispersed gold particles and/or the basic sites derived from the support.

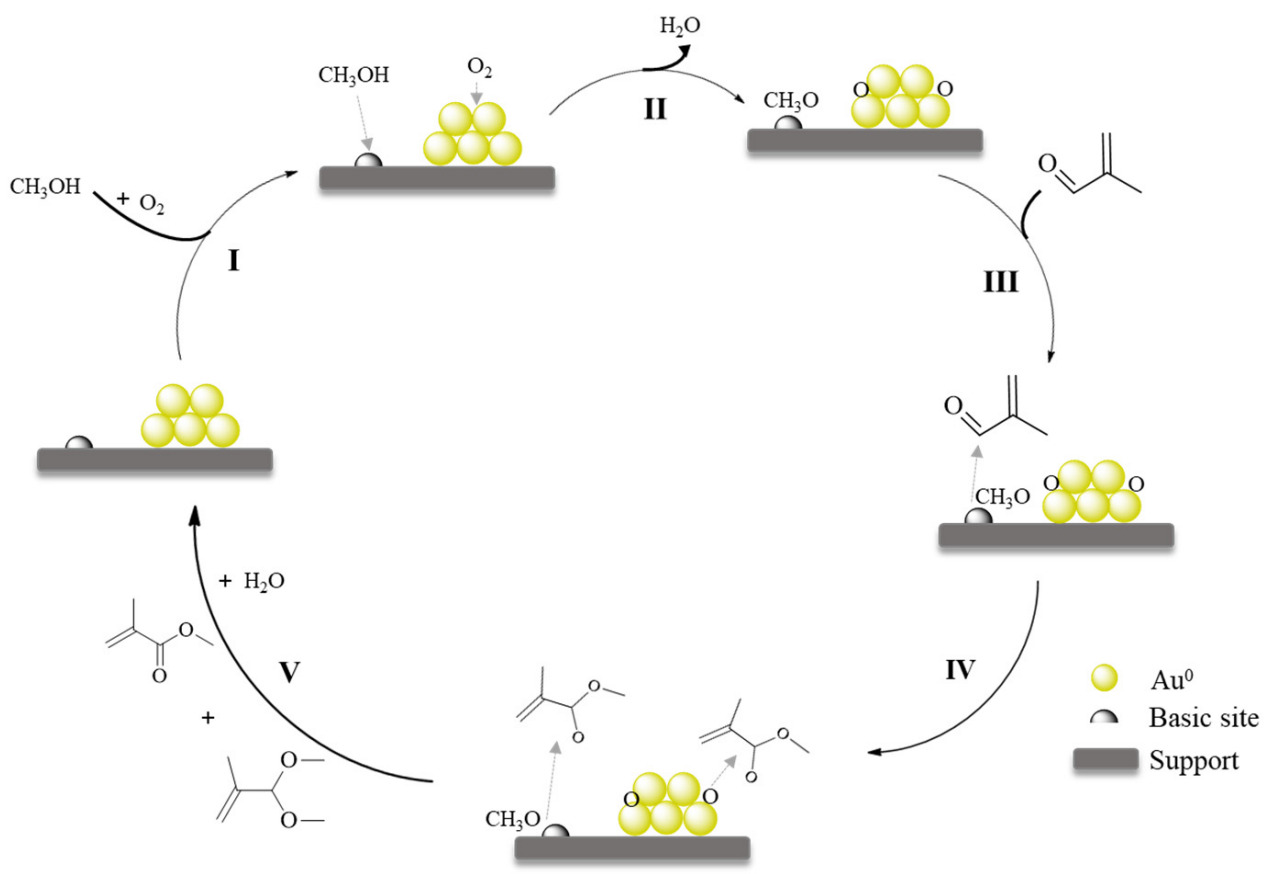

Scheme 3. Reaction pathway of MAL with $\mathrm{MeOH}$ to form MMA.

\subsection{Substrate Universality of the Catalyst}

To examine the effect of the substrates on reactivity, a range of aldehydes and alcohols was extrapolated for one-step oxidative esterification, including isobutyl aldehyde, butyraldehyde, benzaldehyde and, etc. The results are shown in Table 3. As seen, different aldehydes could react with $\mathrm{MeOH}$ or ethanol on the $\mathrm{Au}_{25} / \mathrm{Zn}_{2} \mathrm{Al}-400$ catalysts to form the corresponding esters, indicating the catalyst developed in this study had excellent substrate universality. Thereinto, better activity and selectivity were preferentially achieved over the saturated aldehyde, whereas substrates with a vinyl group or phenyl ring had comparably low activity. Based on the earlier study, the substrates with electron-donating substituents promoted the reaction. In contrast, substrates with electron-withdrawing substituents impeded the formation of ester [18]. 
Table 3. Catalytic performances of various aldehydes and alcohols to form the esters by oxidative esterification over the $\mathrm{Au}_{25} / \mathrm{Zn}_{2} \mathrm{Al}-400$ catalyst.

Entry Alcohol

Reaction conditions: $\mathrm{MAL} / \mathrm{MeOH}=1 / 23$ (molar ratio), $\mathrm{V}(\mathrm{MeOH})=4.5 \mathrm{~mL}$, catalyst: $0.05 \mathrm{~g}, \mathrm{~T}=353 \mathrm{~K}, \mathrm{P}_{\mathrm{O} 2}=3$ atm, $\mathrm{t}=2 \mathrm{~h}$.

\subsection{Stability of Catalysts in Fixed Bed Reactor}

Stability was one of the most important targets for industrial catalysts. Thus, the developed $\mathrm{Au}_{25} / \mathrm{Zn}_{2} \mathrm{Al}-400$ catalyst was then evaluated in a fixed-bed reactor for synthesis of MMA through oxidative esterification. Preliminary, the optimization of reaction conditions was conducted over the $\mathrm{Au}_{25} / \mathrm{Zn}_{2} \mathrm{Al}-400$ catalyst as a function of reaction temperature, gas hourly space velocity (GHSV) and liquid hourly space velocity (LHSV). Their catalytic performances as a consequence of the above factors are shown in Figure 7. Obviously, the catalytic activity and selectivity were largely affected by GHSV (Figure 7b) and LHSV (Figure 7c). In contrast, the temperature seems to make no difference in selectivity (Figure 7a). Based on such results, the reaction conditions at $353 \mathrm{~K}, 2.1 \mathrm{~atm} \mathrm{O}_{2}$, GHSV: $3000 \mathrm{~h}^{-1}$ and LHSV: $10 \mathrm{~h}^{-1}$ were designated for fixed-bed reactor from overall consideration. As seen from the stability results in Figure $7 \mathrm{~d}$, the selectivity of MMA over the $\mathrm{Au}_{25} / \mathrm{Zn}_{2} \mathrm{Al}-400$ catalyst maintained at above $90 \%$ despite the initial drop. Though the activities decreased from $\sim 90 \%$ to $\sim 70 \%$ after $60 \mathrm{~h}$, it tends to get a balance. Thus, the potential application of $\mathrm{Au}_{25} / \mathrm{Zn}_{2} \mathrm{Al}-400$ catalyst for this reaction could be revealed. The same trends were also presented in $\mathrm{Au}_{25} / \mathrm{Zn}_{3} \mathrm{Al}-400$ and $\mathrm{Au}_{25} / \mathrm{Zn}_{1} \mathrm{Al}-400$ catalysts, in which both of the catalysts showed good stabilities in one-step oxidative esterification (Figure S4). 
(a)

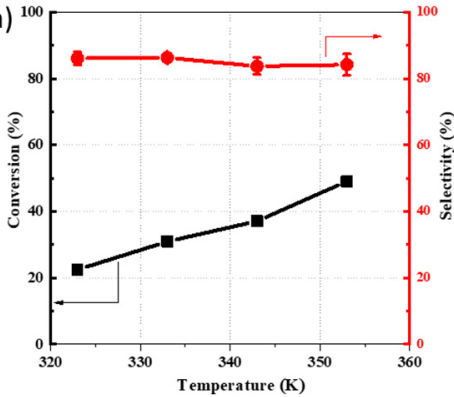

(c)

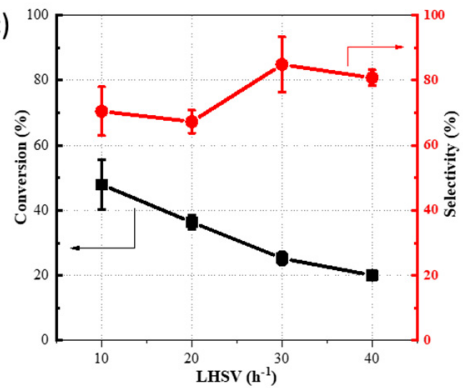

(b)

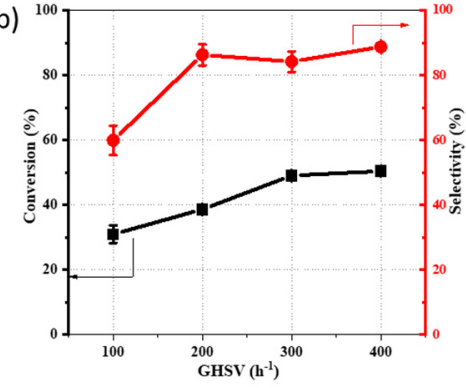

(d)

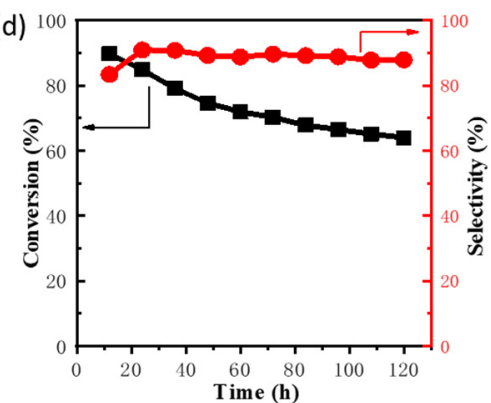

Figure 7. The oxidative esterification performances from MAL and methanol over $\mathrm{Au}_{25} / \mathrm{ZnAl}-400$ catalyst as a function of (a) Reaction temperature at $2.1 \mathrm{~atm} \mathrm{O} \mathrm{O}_{2}, \mathrm{MAL} / \mathrm{MeOH}=1 / 40$ (molar ratio), catalyst: $0.5 \mathrm{~g}$, GHSV: $3000 \mathrm{~h}^{-1}$, LHSV: $10 \mathrm{~h}^{-1}$; (b) gas hourly space velocity (GHSV) at $353 \mathrm{~K}, 2.1 \mathrm{~atm}$ $\mathrm{O}_{2}, \mathrm{MAL} / \mathrm{MeOH}=1 / 40$ (molar ratio), catalyst: $0.5 \mathrm{~g}$, LHSV: $10 \mathrm{~h}^{-1}$, and (c) liquid hourly space velocity (LHSV) at $353 \mathrm{~K}, 2.1 \mathrm{~atm} \mathrm{O}_{2}, \mathrm{MAL} / \mathrm{MeOH}=1 / 40$ (molar ratio), catalyst: $0.5 \mathrm{~g}$, GHSV: $3000 \mathrm{~h}^{-1}$; (d) reaction time at $353 \mathrm{~K}, 2.1 \mathrm{~atm} \mathrm{O}_{2}, \mathrm{MAL} / \mathrm{MeOH}=1 / 40$ (molar ratio), catalyst: $0.5 \mathrm{~g}$, GHSV: $3000 \mathrm{~h}^{-1}$, LHSV: $10 \mathrm{~h}^{-1}$.

\section{Materials and Methods}

\subsection{Chemicals}

All chemicals were used as-received and without any purification. All glassware was washed with Aqua Regia and rinsed with ethanol and ultrapure water. Ultrapure water $(18.2 \mathrm{M} \Omega)$ was used throughout this work. Hydrogen tetrachloroaurate hydrate $\left(\mathrm{HAuCl}_{4} \cdot 3 \mathrm{H}_{2} \mathrm{O}\right)$, sodium carbonate $\left(\mathrm{Na}_{2} \mathrm{CO}_{3}, \mathrm{AR}\right)$, sodium hydroxide $(\mathrm{NaOH}, \mathrm{AR})$, aluminum nitrate hydrate $\left(\left(\mathrm{Al}\left(\mathrm{NO}_{3}\right)_{3} \cdot 9 \mathrm{H}_{2} \mathrm{O}\right), 99 \mathrm{wt} \%\right)$ and methanol were purchased from Sinopharm Company (Beijing, China). Sodium borohydride $\left(\mathrm{NaBH}_{4}, 97 \mathrm{wt} \%\right)$ was purchased from Shanghai Lingfeng Chemical Reagent Company (Shanghai, China). Methacrolein (MAL, $95 \mathrm{wt} \%$ ) was purchased from Shanghai Macklin Biochemical Technology Company (Shanghai, China). Methyl methacrylate (MMA, $99.5 \mathrm{wt} \%$ ), cysteine, zinc nitrate hydrate $\left(\left(\mathrm{Zn}\left(\mathrm{NO}_{3}\right)_{2} \cdot 6 \mathrm{H}_{2} \mathrm{O}\right), 99 \mathrm{wt} \%\right)$ and ortho-xylene $(\mathrm{CP})$ were purchased from Aladdin Industrial Corporation (Shanghai, China).

\subsection{Preparation of the Supported Gold Clusters}

The $\mathrm{Zn}$-Al-HTs supported $\mathrm{Au}_{25}$ nanoclusters catalysts were prepared as follows: $30 \mathrm{mg}$ of the $\mathrm{Au}_{25}$ clusters were dispersed into $20 \mathrm{~mL}$ of ultrapure water. Then, $2.00 \mathrm{~g}$ of the $\mathrm{Zn}$-Al-HTs supports were added into the above suspension under vigorous stirring. About one hour later, the products were washed with ultrapure water and collected by centrifugal separation. Within the process, $\mathrm{Zn}$-Al-HTs and the atomically precisely $\mathrm{Au}_{25}$ nanoclusters were homemade according to our previous work [26-28].

The $\mathrm{Zn}$-Al-HTs were prepared through the coprecipitation method. Typically, $\mathrm{Zn}\left(\mathrm{NO}_{3}\right)_{2} \cdot 6 \mathrm{H}_{2} \mathrm{O}(0.21,0.14$ and $0.07 \mathrm{~mol})$ and $\mathrm{Al}\left(\mathrm{NO}_{3}\right)_{3} \cdot 9 \mathrm{H}_{2} \mathrm{O}(0.07 \mathrm{~mol})$ with $\mathrm{Zn}$-Al atomic ratios of 3, 2, 1 were mixed by adding $200 \mathrm{~mL}$ of ultrapure water to obtain the solution $\mathrm{A}$. $\mathrm{NaOH}(0.438 \mathrm{~mol})$ and $\mathrm{Na}_{2} \mathrm{CO}_{3}(0.113 \mathrm{~mol})$ were placed into a $1000 \mathrm{~mL}$ beaker with $200 \mathrm{~mL}$ of ultrapure water to obtain the solution $\mathrm{B}$. The solution A was slowly pumped into the solution $\mathrm{B}$ in a water bath at $70^{\circ} \mathrm{C}$. Moreover, then, the gel aged at the same temperature 
for another $24 \mathrm{~h}$ at constant stirring. Afterward, the solid was filtered, washed, dried and ground to obtain the $\mathrm{Zn}_{x} \mathrm{Al}-\mathrm{HT}(\mathrm{x}=3,2,1)$.

$\mathrm{Au}_{25}$ clusters were prepared by a $\mathrm{NaOH}$-mediated $\mathrm{NaBH}_{4}$ reduction method [26-28]. First, $5.0 \mathrm{~mL}$ of $\mathrm{HAuCl}_{4}$ solution $(110 \mathrm{mM})$ and $150 \mathrm{~mL}$ of cysteine solution $(5.5 \mathrm{mM})$ were successively added to $200 \mathrm{~mL}$ of ultrapure water under stirring. Then, $30 \mathrm{~mL}$ of $1 \mathrm{M} \mathrm{NaOH}$ solution was introduced into the above mixture at one time. About $5 \mathrm{~min}$ later, fresh sodium borohydride solution was quickly added into the above solution, followed by vigorous stirring for $3 \mathrm{~h}$. Finally, the products were collected and washed with ethanol-water $(\mathrm{V} / \mathrm{V}=3: 1)$ and dried by lyophilization. The obtained dried $\mathrm{Zn}-\mathrm{Al}-\mathrm{HTs}$ supported $\mathrm{Au}_{25}$ nanoclusters samples were defined as $\mathrm{Au}_{25} / \mathrm{Zn}_{x} \mathrm{Al}-\mathrm{HT}$. Before the catalytic test, the samples were calcined at $673 \mathrm{~K}$ for $2 \mathrm{~h}$, with a heating rate of $5{ }^{\circ} \mathrm{C} / \mathrm{min}$. The obtained catalysts were denoted as $\mathrm{Au}_{25} / \mathrm{Zn}_{x} \mathrm{Al}-400$.

\subsection{Preparation of Supported Gold Catalysts with DP Method}

The supported gold catalyst with the same Zn-Al-mixed oxide was prepared by the traditional deposition-precipitation (DP) method. In a typical synthesis, an aqueous solution of $\mathrm{HAuCl}_{4}$ (Au content: $25 \mathrm{~g} / \mathrm{L}, 1 \mathrm{~mL}$ ) was added to a $50 \mathrm{~mL}$ beaker. Then, certain amounts of $\mathrm{Zn}_{2} \mathrm{Al}-\mathrm{HT}$ powders were introduced into the solution under vigorous stirring. After this, $1 \mathrm{M} \mathrm{NaOH}$ solution was added to adjust the $\mathrm{pH}$ value of the suspension liquid to $\sim 10$. Then, the reaction was allowed to proceed at room temperature for $2 \mathrm{~h}$. The obtained solids were washed, dried and calcined at $673 \mathrm{~K}$ for $2 \mathrm{~h}$, with the heating rate of $5{ }^{\circ} \mathrm{C} / \mathrm{min}$. The catalysts produced by this method were denoted as $\mathrm{Au} / \mathrm{Zn}_{2} \mathrm{Al}-400$.

\subsection{Catalytic Test}

Catalytic testing of synthesis of MMA by one-step oxidative esterification of MAL with methanol was carried out in a stainless-steel autoclave equipped with a pressure gauge and magnetic stirring. Before reaction, $0.396 \mathrm{~mL}$ of MAL $(0.96 \mathrm{M}), 0.121 \mathrm{~mL}$ of internal standard (ortho-xylene) and $4.5 \mathrm{~mL}$ of methanol were put into the vessel. Then, certain amounts of catalysts were introduced into the autoclave. After sealing, the autoclave was flushed with oxygen six times and then pressurized at $3 \mathrm{~atm}$. To initiate the reaction, the reactor was heated to $353 \mathrm{~K}$ in a water bath without stirring until the temperature reached the specified value. After the reaction, the autoclave was put into cold water to terminate the reaction. Different substrates of aldehydes and alcohols for the synthesis of esters were conducted in similar conditions. The products and reactants were analyzed by gas chromatography/mass spectrometry (GC, Agilent 7890 A, Wilmington, NC, USA), which was equipped with an HP-5 (30 m, $0.25 \mathrm{~mm}$ inner diameter) capillary column.

\subsection{Stability Test}

The lifetime of the catalyst was performed in a stainless-steel fixed bed reactor (inner diameter, $10.0 \mathrm{~mm}$; length, $660 \mathrm{~mm}$ ) equipped with a K-type thermocouple for control of the reaction temperature and a mass flow controller for regulating the gas flow rate. The feed gas was a mixture of oxygen and nitrogen, with a volume ratio of $7 / 93$. Prior to reaction, $0.5 \mathrm{~g}$ of the $\mathrm{Au}_{25} / \mathrm{Zn}_{x} \mathrm{Al}-400$ catalysts were introduced in the middle of the reactor, with quartz sand placed above and below the catalyst bed to hold it in place. In a typical experiment, a reaction mixture of MAL and methanol (molar ratio: 1/40) was introduced into the system using a double plunger liquid pump. The reaction was carried out under the following conditions: $353 \mathrm{~K}, 3 \mathrm{MPa}$, liquid hourly space velocity (LHSV) $=10 \mathrm{~h}^{-1}$ and gas hourly space velocity (GHSV) $=3000 \mathrm{~h}^{-1}$. Before introducing of reaction mixture into the system, the temperature of the reactor was raised to a specific value. The total pressure of $3 \mathrm{MPa}$ (oxygen partial pressure of $0.21 \mathrm{MPa}$ ) was achieved by regulating the back-pressure valve. The liquid products were analyzed by gas chromatography with a flame ionization detector (FID), which was equipped with an HP-5 capillary column. 


\subsection{Characterization}

The actual loadings of gold, zinc and aluminum were measured with an inductively coupled plasma atomic emission spectroscopy (ICP-AES) on an IRIS Intrepid II XSP instrument (Thermo Electron Corporation, Madison, WI, USA). The X-ray powder diffraction (XRD) patterns were determined on a PW3040/60 X'Pert PRO (PANalytical, Almelo, The Netherlands) diffractometer equipped with a $\mathrm{Cu} \mathrm{K} \alpha$ radiation source $(\lambda=0.15432 \mathrm{~nm})$ operating at $40 \mathrm{kV}$ and $40 \mathrm{~mA}$. The $\mathrm{N}_{2}$-physical adsorption-desorption tests were measured at $77 \mathrm{~K}$ using an AutoSorb-1 instrument (Boynton Beach, FL, USA). Prior to the measurements, the catalysts were treated at vacuum for $2 \mathrm{~h}$ at $120^{\circ} \mathrm{C}$. The transmission electron microscopy (TEM) and high-resolution transmission electron microscopy (HRTEM) were recorded on a JEOL JEM-2100 F (Tokyo, Japan) microscope at $200 \mathrm{kV}$. The in situ diffuse reflectance infrared Fourier-transform spectroscopy of CO adsorption (CO-DRIFTS) were acquired with a Bruker INVENIO Fourier-transform infrared spectrometer (Karlsruhe, Germany), equipped with an MCT detector in the range of $600-4000 \mathrm{~cm}^{-1}$. The X-ray photoelectron spectra (XPS) were conducted on an ESCALAB $250 \mathrm{X}$-ray photoelectron spectrometer (Madison, WI, USA) equipped with a monochromated $\mathrm{Al} \mathrm{K} \alpha$ anode. The binding energies were calibrated for surface charging by referencing them to the energy of the $C 1 \mathrm{~s}$ peak at $285 \mathrm{eV}$. The temperature-programmed desorption of carbon dioxide $\left(\mathrm{CO}_{2}-\mathrm{TPD}\right)$ experiments were performed on Autochem II 2920 Instruments (Norcross, GA, USA) with a thermal conductivity detector and mass spectrometry. Prior to the analysis, about $50 \mathrm{mg}$ of the catalysts were added into a $U$-type quartz tube reactor. Then the samples were heated in a flow of helium at $400{ }^{\circ} \mathrm{C}$ for $0.5 \mathrm{~h}$. After the temperature decreased to $50{ }^{\circ} \mathrm{C}$, the catalysts were saturated with $\mathrm{CO}_{2}$ at $80{ }^{\circ} \mathrm{C}$ for $120 \mathrm{~min}$. Finally, the samples were purged in helium at $50{ }^{\circ} \mathrm{C}$ for $95 \mathrm{~min}$. The $\mathrm{CO}_{2}-\mathrm{TPD}$ signal was recorded from $50{ }^{\circ} \mathrm{C}$ to $1000{ }^{\circ} \mathrm{C}$ at a rate of $10^{\circ} \mathrm{C} / \mathrm{min}$ with a cold trap.

\section{Conclusions}

In summary, $\mathrm{Zn}$-Al-HTs supported $\mathrm{Au}_{25}$ nanoclusters were designed and used as the precursors for direct oxidative esterification of MAL with methanol to form MMA. The $\mathrm{Au}_{25} / \mathrm{Zn}_{\mathrm{x}} \mathrm{Al}-400$ catalysts showed comparable better performances with higher activity and selectivity than the gold catalysts prepared by the DP method. XRD and TEM characterizations suggested that the $\mathrm{Au}_{25} / \mathrm{Zn}_{\mathrm{x}} \mathrm{Al}-400$ catalysts have good dispersion and small average particle sizes of gold. In situ CO DRIFT spectra and Au 4f XPS spectra indicated the metallic gold with strong $\mathrm{CO}$ adsorption property might attribute to this high activity. Moreover, the strong basic sites revealed by $\mathrm{CO}_{2}-\mathrm{TPD}$ were said to facilitate the formation of hemiacetal intermediate, which contributes to the formation of the final product. Combined with the characterization results with catalytic performances, the active sites were supposed to locate at the interface between small gold particles and the support. Further substrate scope experiments and stability test in a fixed-bed reactor suggested the $\mathrm{Au}_{25} / \mathrm{Zn}_{\mathrm{x}} \mathrm{Al}-400$ catalysts have potential in these kinds of reactions. This work also provides a good reference for designing the gold catalyst with high activity and selectivity.

Supplementary Materials: The following are available online at https:/ / www.mdpi.com/2073-4 344/11/2/162/s1, Table S1: Summarization of catalytic performances of supported gold catalysts; Table S2: Element analysis of supported gold catalysts with various Zn/Al molar ratios; Figure S1: $\mathrm{N}_{2}$ adsorption-desorption isotherms and pore size distributions of the supported gold catalysts; Figure S2: Chromatogram analysis of the liquid product before and after oxidative esterification between MAL and $\mathrm{CH}_{3} \mathrm{OH}$; Figure S3: TPD profiles of supported gold catalysts without adsorption of $\mathrm{CO}_{2}$; Figure S4: Stabilities of supported gold catalysts with various $\mathrm{Zn} / \mathrm{Al}$ ratios for the synthesis of MMA from MAL and MeOH.

Author Contributions: Y.T. and Y.D. conceived the study; H.L. performed the experiments; X.C., W.Y. contributed with the materials; J.L. contributed with characterizations; C.H. contributed with the useful advice; All the authors contributed to the writing of the manuscript. All authors have read and agreed to the published version of the manuscript. 
Funding: This research was supported by the National Natural Science Foundation of China under Grant No. 21803056 and 21973084. Zhejiang Provincial Natural Science Foundation of China under Grant No. LQ20B030005 and LQ20B030008.

Data Availability Statement: Data is contained within the article.

Acknowledgments: The authors would like to thank the public testing platform of Zhejiang Normal University and Dalian Institute of Chemical Physics, Chinese Academy of Sciences. Thanks to the technical support with ICP, XRD, TEM, HRTEM and XPS measurements.

Conflicts of Interest: The authors declare no conflict of interest.

\section{References}

1. Nagai, K. New developments in the production of methyl methacrylate. Appl. Catal. A Gen. 2001, 221, 367-377. [CrossRef]

2. Global Industry Analysts Inc, Methyl Methacrylate (MMA)—Global Market Trajectory Analytics. Available online: https: //www.researchandmarkets.com/categories/chemicals-materials (accessed on 5 December 2020).

3. Wang, B.; Li, H.; Zhu, J.; Sun, W.; Chen, S. Preparation and characterization of mono-/multi-metallic hydrophobic catalysts for the oxidative esterification of methacrolein to methyl methacrylate. J. Mol. Catal. A Chem. 2013, 379, 322-326. [CrossRef]

4. Tian, Y.; Li, Y.; Zuo, C.; Yin, D.; Wang, L.; Zheng, Y.; Huang, H.; Fu, Z.; Wang, M. Ionic-Liquid-Modified Porous Au/CeMnOx Nanorods for Methyl Methacrylate (MMA) Synthesis via Direct Oxidative Esterification. Chemnanomat 2019, 5, 1361-1366. [CrossRef]

5. Diao, Y.; He, H.; Yang, P.; Wang, L.; Zhang, S. Optimizing the structure of supported Pd catalyst for direct oxidative esterification of methacrolein with methanol. Chem. Eng. Sci. 2015, 135, 128-136. [CrossRef]

6. Diao, Y.; Yang, P.; Yan, R.; Jiang, L.; Wang, L.; Zhang, H.; Li, C.; Li, Z.; Zhang, S. Deactivation and regeneration of the supported bimetallic $\mathrm{Pd}-\mathrm{Pb}$ catalyst in direct oxidative esterification of methacrolein with methanol. Appl. Catal. B Environ. 2013, 142, 329-336. [CrossRef]

7. Mahboub, M.J.D.; Dubois, J.-L.; Cavani, F.; Rostamizadeh, M.; Patience, G.S. Catalysis for the synthesis of methacrylic acid and methyl methacrylate. Chem. Soc. Rev. 2018, 47, 7703-7738. [CrossRef] [PubMed]

8. Yamamatsu, S.; Yamaguchi, T.; Yokota, K.; Nagano, O.; Chono, M.; Aoshima, A. Development of Catalyst Technology for Producing Methyl Methacrylate (MMA) by Direct Methyl Esterification. Catal. Surv. Asia 2010, 14, 124-131. [CrossRef]

9. Min, B.K.; Friend, C.M. Heterogeneous Gold-Based Catalysis for Green Chemistry: Low-Temperature CO Oxidation and Propene Oxidation. Chem. Rev. 2007, 107, 2709-2724. [CrossRef]

10. Liu, S.Y.; Yang, S.M. Complete oxidation of 2-propanol over gold-based catalysts supported on metal oxides. Appl. Catal. A Gen. 2008, 334, 92-99. [CrossRef]

11. Turner, M.; Golovko, V.B.; Vaughan, O.P.H.; Abdulkin, P.; Berenguer-Murcia, A.; Tikhov, M.S.; Johnson, B.F.G.; Lambert, R.M. Selective oxidation with dioxygen by gold nanoparticle catalysts derived from 55-atom clusters. Nat. Cell Biol. 2008, 454, 981-983. [CrossRef]

12. Zhang, Y.; Cui, X.; Shi, F.; Deng, Y. Nano-Gold Catalysis in Fine Chemical Synthesis. Chem. Rev. 2011, 112, 2467-2505. [CrossRef] [PubMed]

13. Tan, Y.; Liu, H.; Liu, X.Y.; Wang, A.; Liu, C.; Zhang, T. Effective removal of the protective ligands from Au nanoclusters by ambient pressure nonthermal plasma treatment for CO oxidation. Chin. J. Catal. 2018, 39, 929-936. [CrossRef]

14. Liu, L.; Li, H.; Tan, Y.; Chen, X.; Lin, R.; Yang, W.; Huang, C.; Wang, S.; Wang, X.; Liu, X.Y.; et al. Metal-Support Synergy of Supported Gold Nanoclusters in Selective Oxidation of Alcohols. Catalysts 2020, 10, 107. [CrossRef]

15. Suzuki, K.; Yamaguchi, T.; Matsushita, K.; Iitsuka, C.; Miura, J.; Akaogi, T.; Ishida, H. Aerobic Oxidative Esterification of Aldehydes with Alcohols by Gold-Nickel Oxide Nanoparticle Catalysts with a Core-Shell Structure. ACS Catal. 2013, 3, 1845-1849. [CrossRef]

16. Wan, X.; Deng, W.; Zhang, Q.; Wang, Y. Magnesia-supported gold nanoparticles as efficient catalysts for oxidative esterification of aldehydes or alcohols with methanol to methyl esters. Catal. Today 2014, 233, 147-154. [CrossRef]

17. Li, Y.; Wang, L.; Yan, R.; Han, J.; Zhang, S. Gold nanoparticles supported on Ce-Zr oxides for the oxidative esterification of aldehydes to esters. Catal. Sci. Technol. 2015, 5, 3682-3692. [CrossRef]

18. Zuo, C.; Tian, Y.; Zheng, Y.; Wang, L.; Fu, Z.; Jiao, T.; Wang, M.; Huang, H.; Li, Y. One step oxidative esterification of methacrolein with methanol over Au-CeO2/ $\gamma$-Al2O3 catalysts. Catal. Commun. 2019, 124, 51-55. [CrossRef]

19. Tian, Y.; Li, Y.; Zheng, Y.; Wang, M.; Zuo, C.; Huang, H.; Yin, D.; Fu, Z.; Tan, J.; Zhou, Z. Nano-Au/MCeOx catalysts for the direct oxidative esterification of methylacrolein to methyl esters. Ind. Eng. Chem. Res. 2019, 58, 19397-19405. [CrossRef]

20. Paul, B.; Khatun, R.; Sharma, S.K.; Adak, S.; Singh, G.; Das, D.; Siddiqui, N.; Bhandari, S.; Joshi, V.; Sasaki, T.; et al. Fabrication of Au Nanoparticles Supported on One-Dimensional La2O3 Nanorods for Selective Esterification of Methacrolein to Methyl Methacrylate with Molecular Oxygen. ACS Sustain. Chem. Eng. 2019, 7, 3982-3994. [CrossRef]

21. Gao, J.; Fan, G.; Yang, L.; Cao, X.; Zhang, P.; Li, F. Oxidative Esterification of Methacrolein to Methyl Methacrylate over Gold Nanoparticles on Hydroxyapatite. Chem CatChem 2017, 9, 1230-1241. [CrossRef] 
22. Li, H.; Li, J.; Tan, Y.; Ding, Y. Research progress on the production technology and noble metal catalyst for synthesis of methyl methacrylate. Chem. Ind. Eng. Prog. 2021, 40, 183-194.

23. Seftel, E.; Popovici, E.; Mertens, M.; De Witte, K.; Van Tendeloo, G.; Cool, P.; VanSant, E.F. Zn-Al layered double hydroxides: Synthesis, characterization and photocatalytic application. Microporous Mesoporous Mater. 2008, 113, 296-304. [CrossRef]

24. Hernández, W.Y.; Aliç, F.; Verberckmoes, A.; Van Der Voort, P. Tuning the acidic-basic properties by Zn-substitution in Mg-Al hydrotalcites as optimal catalysts for the aldol condensation reaction. J. Mater. Sci. 2016, 52, 628-642. [CrossRef]

25. Fang, L.; Luo, W.; Meng, Y.; Zhou, X.; Pan, G.; Ni, Z.; Xia, S. Visible-Light-Promoted Selective Hydrogenation of Crotonaldehyde by Au Supported ZnAl-Layered Double Hydroxides: Catalytic Property, Kinetics, and Mechanism Investigation. J. Phys. Chem. C 2018, 122, 17358-17369. [CrossRef]

26. Fang, W.; Chen, J.; Zhang, Q.; Deng, W.; Wang, Y. Hydrotalcite-Supported Gold Catalyst for the Oxidant-Free Dehydrogenation of Benzyl Alcohol: Studies on Support and Gold Size Effects. Chem. A Eur. J. 2010, 17, 1247-1256. [CrossRef] [PubMed]

27. Turco, M.; Bagnasco, G.; Costantino, U.; Marmottini, F.; Montanari, T.; Ramis, G.; Busca, G. Production of hydrogen from oxidative steam reforming of methanolII. Catalytic activity and reaction mechanism on $\mathrm{Cu} / \mathrm{ZnO} / \mathrm{Al}_{2} \mathrm{O}_{3}$ hydrotalcite-derived catalysts. J. Catal. 2004, 228, 56-65. [CrossRef]

28. Kirm, I.; Medina, F.; Rodríguez, X.; Cesteros, Y.; Salagre, P.; Sueiras, J. Epoxidation of styrene with hydrogen peroxide using hydrotalcites as heterogeneous catalysts. Appl. Catal. A Gen. 2004, 272, 175-185. [CrossRef]

29. Tan, Y.; Liu, X.; Zhang, L.; Wang, A.; Li, L.; Pan, X.; Miao, S.; Haruta, M.; Wei, H.; Wang, H.; et al. ZnAl-Hydrotalcite-Supported Au25 Nanoclusters as Precatalysts for Chemoselective Hydrogenation of 3-Nitrostyrene. Angew. Chem. Int. Ed. 2017, 56, 2709-2713. [CrossRef]

30. Tan, Y.; Liu, X.Y.; Li, L.; Kang, L.; Wang, A.; Zhang, T. Effects of divalent metal ions of hydrotalcites on catalytic behavior of supported gold nanocatalysts for chemoselective hydrogenation of 3-nitrostyrene. J. Catal. 2018, 364, 174-182. [CrossRef]

31. Tan, Y.; Liu, X.Y.; Zhang, L.; Liu, F.; Wang, A.; Zhang, T. Producing of cinnamyl alcohol from cinnamaldehyde over supported gold nanocatalyst. Chin. J. Catal. 2021, 42, 470-481. [CrossRef]

32. Sing, K.S.; Williams, R.T. Physisorption Hysteresis Loops and the Characterization of Nanoporous Materials. Adsorpt. Sci. Technol. 2004, 22, 773-782. [CrossRef]

33. Włodarczyk-Stasiak, M.; Jamroz, J. Specific surface area and porosity of starch extrudates determined from nitrogen adsorption data. J. Food Eng. 2009, 93, 379-385. [CrossRef]

34. Mihaylov, M.Y.; Knözinger, H.; Hadjiivanov, K.; Gates, B.C. Characterization of the Oxidation States of Supported Gold Species by IR Spectroscopy of Adsorbed CO. Chem. Ing. Tech. 2007, 79, 795-806. [CrossRef]

35. George, G.; Saravanakumar, M. Correction to: Facile synthesis of carbon-coated layered double hydroxide and its comparative characterisation with $\mathrm{Zn}-\mathrm{Al} \mathrm{LDH}$ : Application on crystal violet and malachite green dye adsorption-Isotherm, kinetics and Box-Behnken design. Environ. Sci. Pollut. Res. 2018, 25, 30255-30256. [CrossRef] [PubMed]

36. Gil, J.J.; Aguilar-Martínez, O.; Piña-Pérez, Y.; Pérez-Hernández, R.; Santolalla-Vargas, C.E.; Gómez, R.; Tzompantzi, F. Efficient $\mathrm{ZnS}-\mathrm{ZnO} / \mathrm{ZnAl}-\mathrm{LDH}$ composite for H2 production by photocatalysis. Renew. Energy 2020, 145, 124-132. [CrossRef]

37. Zhang, Z.; Hua, Z.; Lang, J.; Song, Y.; Zhang, Q.; Han, Q.; Fan, H.; Gao, M.; Li, X.; Fan, H. Eco-friendly nanostructured Zn-Al layered double hydroxide photocatalysts with enhanced photocatalytic activity. CrystEngComm 2019, 21, 4607-4619. [CrossRef]

38. Trimpalis, A.; Giannakakis, G.; Cao, S.; Flytzani-Stephanopoulos, M. NiAu single atom alloys for the selective oxidation of methacrolein with methanol to methyl methacrylate. Catal. Today 2020, 355, 804-814. [CrossRef]

39. Li, J.; Chao, H.; Kai, T.; Hao, X.; Zhu, Z.; Hu, Z. CO2 atmosphere-enhanced methanol aromatization over the NiO-HZSM-5 catalyst. Rsc. Adv. 2014, 4, 44377-44385. [CrossRef]

40. Shi, Q.; Qin, Z.; Xu, H.; Li, G. Heterogeneous Cross-Coupling over Gold Nanoclusters. Nanomaterials 2019, 9, 838. [CrossRef]

41. Taketoshi, A.; Haruta, M. ChemInform Abstract: Size- and Structure-Specificity in Catalysis by Gold Clusters. Chem. Lett. 2014, 45, 380-387. [CrossRef]

42. Xu, B.; Liu, X.; Haubrich, J.; Friend, C.M. Vapour-phase gold-surface-mediated coupling of aldehydes with methanol. Nat. Chem. 2009, 2, 61-65. [CrossRef] [PubMed] 